\title{
The Numerical Simulation of non-Darcy Flow for YuShulin Low Permeability Oilfield
}

\author{
Yin Daiyin, Zhou Yazhou, Yuan He and Zhang Chengli \\ Northeast Petroleum University, Heilongjiang, China \\ yindaiyin@163.com,zhouyazhou720@163.com,jlyuan12@163.com, \\ zhangchengli0303@163.com
}

\begin{abstract}
In this paper, a mathematical model for non-Darcy flow in low permeability oil reservoirs is developed, considering the threshold pressure gradient. The model is then discretized into difference equations and solved. FORTAN99 language is used to program the $3 D$ three-phase numerical model for non-Darcy flow in the simulation software. FORTAN99 is used, because it is fast when performing huge engineering calculations. The pre and post processing system for the simulation software is developed using DELPHI language, because it has good interface with WINDOWS and has ability to manage databases. Numerical simulation is done in the simulation software combined with actual data from Yushulin low permeability oilfield. The effects of threshold pressure gradient, well spacing, and water injection modes are investigated. Results show that as the permeability increases from $1 \times 10^{-3} \mu \mathrm{m}^{2}$ to $12 \times 10^{-3} \mathrm{\mu m}^{2}$, the sweep efficiency and the water displacement recovery also increases significantly. When the permeability of reservoir is fixed at $5 \times 10^{-3} \mathrm{\mu m}^{2}$, the threshold pressure gradient increases as the well spacing decreases from $350 \mathrm{~m}$ to $150 \mathrm{~m}$. Compared with the inverted nine spot water injection pattern, the sweep efficiencies for the line water injection pattern and the fivespot water injection pattern increase by $6.64 \%$ and $7.78 \%$, respectively. The water displacement recoveries for them are increased by $2.94 \%$ and $3.57 \%$, respectively.
\end{abstract}

Keywords: computer numerical simulation; Non-Darcy flow; mathematical model; low permeability oilfield

\section{Introduction}

During the development of a reservoir, the threshold pressure phenomenon commonly exists when oil and water seeps, especially in low permeability reservoirs. Since low permeability reservoirs have threshold pressure gradient, the water injection mode and well spacing not only affect the control of water displacement, but also influence the effective driving coefficient [1]. When the well spacing exceeds a certain value, the driving pressure gradient becomes smaller than the threshold pressure gradient. Then this part of oil cannot receive enough driving pressure to move. Studying threshold pressure can provide more realistic guidance on the layer series of development division and well network deployment. It also provides a new methodology for the research of interlayer reserve utilization. Therefore, the effects of threshold pressure should be considered in the numerical simulation. Currently most commercial numerical simulation software does not consider the effects of threshold pressure. In this paper, numerical simulations of non-Darcy flow in low permeability reservoirs are used to quantitatively analyze the effect of injection pattern and threshold pressure gradient on the effective driving coefficient and water displacement recovery. 


\section{Mathematical Model for non-Darcy Flow with the Consideration of Threshold Pressure Gradient}

\subsection{Basic Equations}

It is assumed that there is a multi-phase system at constant temperature with oil, water, and gas phases. The isothermal three-phase system can be described using three mass balance equations. For any region, the mass balances can be written as:

Oil phase:

$$
\frac{\partial}{\partial t}\left(\phi S_{\mathrm{o}} \bar{\rho}_{\mathrm{o}}\right)=-\nabla \cdot\left(\bar{\rho}_{\mathrm{o}} V_{\mathrm{o}}\right)+q_{\mathrm{o}}
$$

Water phase:

$$
\frac{\partial}{\partial t}\left(\phi S_{\mathrm{w}} \rho_{\mathrm{w}}\right)=-\nabla \cdot\left(\rho_{\mathrm{w}} V_{\mathrm{w}}\right)+q_{\mathrm{w}}
$$

Gas phase:

$$
\frac{\partial}{\partial t}\left\{\phi\left(S_{\mathrm{o}} \bar{\rho}_{\mathrm{dg}}+S_{\mathrm{g}} \rho_{\mathrm{g}}\right)\right\}=-\nabla \cdot\left(\bar{\rho}_{\mathrm{dg}} V_{\mathrm{o}}+\rho_{\mathrm{g}} V_{\mathrm{g}}\right)+q_{\mathrm{g}}
$$

\subsection{Basic Relations}

The three-phase mass balance equations need to be complemented by some fundamental equations as follows.

\subsubsection{Equation for velocity of non-Darcy flow:}

$$
V_{l}=-\frac{k k_{\mathrm{r} l}}{\mu_{l}}\left(\nabla P_{l}-\rho_{l} \mathrm{~g} \nabla D-G(k)\right)
$$

Where $V_{l}$ is velocity of non-Darcy flow; $l$ can be $\mathrm{o}, \mathrm{w}$, or $\mathrm{g}$, which stands for oil phase, water phase, or gas phase, respectively; $\rho_{l}$ is the density under current reservoir condition for the $l$ phase, $\mathrm{kg} / \mathrm{m}^{3} ; \mu_{l}$ is the viscosity for the $l$ phase , $\mathrm{mPa} \cdot \mathrm{s} ; S_{l}$ is the percentage of saturation for the 1 phase; $P_{l}$ is the pressure for the $l$ phase, MPa; $k$ is the absolute permeability, $10^{-3} \mu \mathrm{m}^{2}$; $k_{r l}$ is the relative permeability for the $l$ phase; $\nabla D$ is taken as 1 , and downward is chosen as the positive direction of z-axis; $G(k)$ is the threshold pressure gradient, $\mathrm{MPa} / \mathrm{m}$ 。

Considering the threshold pressure of the flow, the Darcy equation is:

$$
V_{l}=-\frac{k k_{r l}}{\mu_{l}}\left(\nabla \Phi_{l} \pm G(k)\right)
$$

Based on the physical meaning of threshold pressure gradient:

$$
V_{l}=-\frac{k k_{r l}}{\mu_{l}}\left(\nabla \Phi_{l}-G(k)\right) \quad \nabla \Phi_{l}>G(k)
$$




$$
\begin{gathered}
V_{l}=-\frac{k k_{r l}}{\mu_{l}}\left(\nabla \Phi_{l}+G(k)\right) \quad \nabla \Phi_{l}<-G(k) \\
V_{l}=0 \quad-G(k) \leq \nabla \Phi_{l} \leq G(k)
\end{gathered}
$$

2.1.2. Constraint conditions of saturation: Constraint conditions of saturation is:

$$
S_{\mathrm{w}}+S_{\mathrm{o}}+S_{\mathrm{g}}=1
$$

2.1.3. Capillary Pressure: The pressure of different phases needs to be connected by capillary pressure. The relationship between the water phase pressure and the gas phase pressure is:

$$
P_{\mathrm{w}}=P_{\mathrm{g}}-P_{\mathrm{cgw}}\left(S_{\mathrm{w}}\right)
$$

The relationship between the oil phase pressure and the gas phase pressure is:

$$
P_{\mathrm{o}}=P_{\mathrm{g}}-P_{\text {cgo }}\left(S_{\mathrm{w}}, S_{\mathrm{o}}\right)
$$

Where: $P_{\text {cgw }}$ is the gas-water capillary pressure of the three phase system, which is a function of the water saturation; $P_{\text {cgo }}$ is the gas-oil capillary pressure of the three phase system, which is a function of the oil saturation

Based on the basic properties of most reservoirs, the order of wetting is 1) water phase 2) oil phase 3) gas phase. The gas-water capillary pressure is generally higher than the gas-oil capillary pressure. The oil-water capillary pressure of the three phase system is defined as:

$$
P_{\text {cow }}=P_{\text {cgw }}-P_{\text {cgo }}=P_{\mathrm{o}}-P_{\mathrm{w}}
$$

In the simulation software, the function used for capillary pressure is found by table lookup [2]. Parker et al., suggested making modifications to the function for capillary pressure as:

$$
\begin{gathered}
P_{\mathrm{cow}}^{\mathrm{ow}}=\frac{\rho_{\mathrm{w}} \mathrm{g}}{\alpha_{\mathrm{ow}}}\left[\left(\bar{S}_{\mathrm{w}}\right)^{-1 / \gamma}-1\right]^{1 / \beta} \\
P_{\mathrm{cgo}}^{\mathrm{go}}=\frac{\rho_{\mathrm{w}} \mathrm{g}}{\alpha_{\mathrm{go}}}\left[\left(1-\bar{S}_{\mathrm{g}}\right)^{-1 / \gamma}-1\right]^{1 / \beta} \\
P_{\mathrm{cgw}}^{\mathrm{gw}}=\frac{\rho_{\mathrm{w}} \mathrm{g}}{\alpha_{\mathrm{gw}}}\left[\left(1-\bar{S}_{\mathrm{g}}\right)^{-1 / \gamma}-1\right]^{1 / \beta}
\end{gathered}
$$

Where $\gamma$ and $\beta$ are parameters in the Van Genuchten function, $\gamma=1-1 / \beta$, and

$$
\begin{aligned}
& \alpha_{\mathrm{ow}}=\alpha_{v G} \frac{\sigma_{\mathrm{gw}}}{\sigma_{\mathrm{ow}}} \\
& \alpha_{\mathrm{go}}=\alpha_{v G} \frac{\sigma_{\mathrm{gw}}}{\sigma_{\mathrm{go}}}
\end{aligned}
$$




$$
\begin{gathered}
\alpha_{\mathrm{gw}}=\alpha_{\mathrm{vG}} \\
\bar{S}_{w}=\frac{S_{\mathrm{w}}-S_{\mathrm{wr}}}{1-S_{\mathrm{wr}}} \\
\bar{S}_{\mathrm{g}}=\frac{S_{\mathrm{g}}}{1-S_{\mathrm{wr}}}
\end{gathered}
$$

Where: $\alpha_{v \mathrm{G}}$ is the parameter $\alpha$ in van Genuchten function; $\sigma_{\mathrm{gw}}, \sigma_{\mathrm{ow}}$, and $\sigma_{\mathrm{go}}$ are interfacial tension of gas-water, oil-water, and gas-oil respectively, $\mathrm{mN} / \mathrm{m}$.

2.1.4. Function for relative permeability: Assuming that the relative permeability is only a function of fluid saturation, the relative permeability can then be expressed as:

Oil phase:

$$
k_{\text {ro }}=k_{\text {ro }}\left(S_{\mathrm{w}}, S_{\mathrm{g}}\right)
$$

Water phase:

$$
k_{\mathrm{rw}}=k_{\mathrm{rw}}\left(S_{\mathrm{w}}\right)
$$

Gas phase:

$$
k_{\mathrm{rg}}=k_{\mathrm{rg}}\left(S_{\mathrm{g}}\right)
$$

When the relative permeability is unknown for all three phases, the relative permeability of oil phase can be found through the method proposed by Stone's method:

$$
k_{\mathrm{ro}}=k_{\mathrm{ro}}^{* \text { wo }}\left[\left(k_{\mathrm{ro}}^{\mathrm{wo}} / k_{\mathrm{ro}}^{*{ }_{\text {wo }}}+k_{\mathrm{rw}}\right)\left(k_{\mathrm{ro}}^{\mathrm{og}} / k_{\mathrm{ro}}^{* \text { wo }}+k_{\mathrm{rg}}\right)-\left(k_{\mathrm{rw}}+k_{\mathrm{rg}}\right)\right]
$$

Where $k_{\mathrm{ro}}^{* \text { wo }}$ is the relative permeability of oil with respect to the residual oil-water relative permeability; $k_{\text {ro }}^{\text {wo }}$ is the relative permeability of oil with respect to the oil-water relative permeability; $k_{\mathrm{ro}}^{\mathrm{og}}$ is the relative permeability of gas with respect to the oil-gas relative permeability. From the function of StoneII (24), the relative permeability of the three phase system can be calculated from the water-oil and oil-gas systems.

In the simulation software, there are two more methods to calculate the relative permeability. One of the options is an extension of the Brooks-Corey function to three phases:

$$
\begin{gathered}
k_{\mathrm{rw}}=\left(\bar{S}_{\mathrm{w}}\right)^{2+\varphi} \\
\left.k_{\mathrm{ro}}=\left[\bar{S}_{\mathrm{o}}-\bar{S}_{\mathrm{rr}}\right]^{2} \mid\left[\bar{S}_{\mathrm{L}}\right)^{\varphi}-\left(\bar{S}_{\mathrm{w}}\right)^{\varphi}\right] \\
\left.k_{\mathrm{rg}}=\left[\bar{S}_{\mathrm{g}}\right]^{2} \mid 1-\left(\bar{S}_{\mathrm{L}}\right)^{\varphi}\right]
\end{gathered}
$$

Where $\bar{S}_{\mathrm{w}}$ is defined in equation (19), $\varphi=1+2 / \lambda$ where $\lambda$ is the Brook-Corey pore size distribution coefficient, and 


$$
\begin{aligned}
& \bar{S}_{\mathrm{o}}=\frac{S_{\mathrm{o}}}{1-S_{\mathrm{wr}}} \\
& \bar{S}_{\text {or }}=\frac{S_{\text {or }}}{1-S_{\mathrm{wr}}} \\
& \bar{S}_{\mathrm{g}}=\frac{S_{\mathrm{g}}-S_{\mathrm{gr}}}{1-S_{\mathrm{wr}}} \\
& \bar{S}_{\mathrm{L}}=\bar{S}_{\mathrm{w}}+\bar{S}_{\mathrm{o}}
\end{aligned}
$$

Where: $S_{\text {or }}$ is the residual oil saturation; $S_{\mathrm{gr}}$ is the irreducible gas saturation.

The other option is to extend the van Genuchten model to express relative permeability in a three-phase system:

$$
\begin{gathered}
\mathrm{k}_{\mathrm{rw}}=\left(\overline{\mathrm{S}}_{\mathrm{w}}\right)^{1 / 2}\left\{1-\left(1-\left(\overline{\mathrm{S}}_{\mathrm{w}}\right)^{1 / \gamma}\right)^{\gamma}\right\}^{2} \\
k_{\mathrm{ro}}=\left(\bar{S}_{\mathrm{o}}-\bar{S}_{\mathrm{or}}\right)^{1 / 2}\left\{\left(1-\left(\bar{S}_{\mathrm{w}}\right)^{1 / \gamma}\right)^{\gamma}-\left(1-\left(\bar{S}_{\mathrm{L}}\right)^{1 / \gamma}\right)^{\gamma}\right\}^{2} \\
k_{\mathrm{rg}}=\left(\bar{S}_{\mathrm{g}}\right)^{1 / 2}\left[1-\left(\bar{S}_{\mathrm{L}}\right)^{1 / \gamma}\right]^{2 \gamma}
\end{gathered}
$$

2.1.5. PVT data: The densities of oil, gas, and water under the reservoir conditions can be expressed as a function of the reservoir volume factor, for oil phase:

$$
\rho_{\mathrm{o}}=\frac{1}{B_{\mathrm{o}}}\left[\left(\rho_{\mathrm{o}}\right)_{\mathrm{STC}}+R_{\mathrm{s}}\left(\rho_{\mathrm{g}}\right)_{\mathrm{STC}}\right]=\bar{\rho}_{\mathrm{o}}+\bar{\rho}_{\mathrm{dg}}
$$

For water phase:

$$
\rho_{\mathrm{w}}=\frac{\left(\rho_{\mathrm{w}}\right)_{\mathrm{STC}}}{B_{\mathrm{w}}}
$$

For gas phase:

$$
\rho_{\mathrm{g}}=\frac{\left(\rho_{\mathrm{g}}\right)_{\mathrm{STC}}}{B_{\mathrm{g}}}
$$

Where $B_{l}$ is the formation volume factor for the $l$ phase; $\left(\rho_{l}\right)_{\text {STC }}$ is the density under standard conditions for the $l$ phase, $\mathrm{kg} / \mathrm{m}^{3} ; R_{s}$ is the dissolved gas/oil ratio, $\mathrm{m}^{3} / \mathrm{m}^{3}$.

Also note that

$$
\bar{\rho}_{\mathrm{o}}=\frac{\left(\rho_{\mathrm{o}}\right)_{\mathrm{STC}}}{B_{\mathrm{o}}}
$$




$$
\begin{gathered}
\bar{\rho}_{\mathrm{dg}}=\frac{R_{\mathrm{s}}\left(\rho_{\mathrm{g}}\right)_{\mathrm{STC}}}{B_{\mathrm{o}}} \\
B_{\mathrm{o}}=\frac{\left(v_{\mathrm{o}}+v_{\mathrm{dg}}\right)_{\mathrm{RC}}}{\left(v_{\mathrm{o}}\right)_{\mathrm{STC}}} \\
B_{\mathrm{w}}=\frac{\left(v_{\mathrm{w}}\right)_{\mathrm{RC}}}{\left(v_{\mathrm{w}}\right)_{\mathrm{STC}}} \\
B_{\mathrm{g}}=\frac{\left(v_{\mathrm{g}}\right)_{\mathrm{RC}}}{\left(v_{\mathrm{g}}\right)_{\mathrm{STC}}} \\
R_{\mathrm{s}}=\left[\frac{v_{\mathrm{dg}}}{v_{\mathrm{o}}}\right]_{\mathrm{STC}}
\end{gathered}
$$

Where $\left(v_{l}\right)_{\mathrm{RC}}$ is volume of the $l$ phase under reservoir condition for given mass, $\mathrm{m}^{3}$; $\left(v_{l}\right)_{\mathrm{STC}}$ is volume of the same mass under standard conditions of the $l$ phase, $\mathrm{m}^{3}$.

Generally for a three-phase reservoir, the formation volume factor and the dissolved gas/oil ratio are functions of the reservoir pressure and the bubble point pressure. The following function is used in the simulation software:

$$
\begin{gathered}
B_{\mathrm{o}}=B_{\mathrm{o}}\left(P_{\mathrm{o}}, P_{\mathrm{b}}\right) \\
B_{\mathrm{g}}=B_{\mathrm{g}}\left(P_{\mathrm{g}}\right) \\
B_{\mathrm{w}}=\frac{B_{\mathrm{w}}^{\mathrm{o}}}{1+C_{\mathrm{w}}\left(P_{\mathrm{w}}-P_{\mathrm{b}}^{\mathrm{o}}\right)} \\
R_{\mathrm{s}}=R_{\mathrm{s}}\left(P_{\mathrm{o}}, P_{\mathrm{b}}\right)
\end{gathered}
$$

Where $P_{\mathrm{b}}$ is the reservoir bubble point pressure; $B_{\mathrm{w}}^{\mathrm{o}}$ is the water phase formation volume factor under the original bubble point pressure $P_{\mathrm{b}}^{\mathrm{o}} ; C_{\mathrm{w}}$ is the coefficient of compressibility of water phase, $1 / \mathrm{MPa}$.

When modeling with the simulation software, the relationship among reservoir pressure, bubble point pressure, reservoir formation volume factor and dissolved gas/oil ratio is used. These parameters can be obtained by analysis of PVT data.

2.1.6. Fluid viscosity: The gas phase is treated as a Newtonian fluid, so that its viscosity is only a function of pressure.

$$
\mu_{\mathrm{g}}=\mu_{\mathrm{g}}\left(P_{\mathrm{g}}\right)
$$


The oil phase is also assumed to be a Newtonian fluid, and its viscosity can be expressed as:

$$
\mu_{\mathrm{o}}=\mu_{\mathrm{o}}\left(P_{\mathrm{o}}\right)
$$

This is a function of the reservoir pressure.

2.1.7. Formation porosity: The effective porosity of rock formation is seen as a function of pressure and reservoir temperature:

$$
\phi=\varphi^{\mathrm{o}}\left(1+C_{\mathrm{r}}\left(P-\mathrm{P}^{\mathrm{o}}\right)-C_{\mathrm{T}}\left(T-\mathrm{T}^{\mathrm{o}}\right)\right)
$$

Where: $\phi^{\circ}$ is the porosity under reference pressure $P^{\mathrm{o}}$ and reference temperature $T^{\mathrm{o}} ; C_{\mathrm{r}}$ is the coefficient of compressibility of rock formation, $1 / \mathrm{MPa}$.

\section{Numerical Solutions of the Model}

The numerical method used in the proposed software is the finite difference method. The mass balance equations for oil, gas, and water phases are discretized to a series of finite difference equations [3]. The implicit method gives a stable solution and a longer time step or, alternatively, an adaptive implicit method can be used to accelerate the simulation time and reduce the usage of the memory. The thermodynamic data of fluid and rocks are approximated using the mass flow rates between connected grid blocks by the finite difference method. The discrete nonlinear difference mass balance equations are solved using Newton-Raphson method.

The continuity equations are discretized using finite difference method in space domain. Backward finite difference is used for time domain discretization. The discretized nonlinear equations for node $i$ is shown below.

Oil phase:

$$
\left\{\left[\varphi S_{\mathrm{o}} \bar{\rho}_{\mathrm{o}}\right]_{i}^{n+1}-\left[\varphi S_{\mathrm{o}} \bar{\rho}_{\mathrm{o}}\right]_{i}^{n}\right\} \frac{V_{i}}{\Delta t}=\sum_{j \in \eta_{i}}\left(\bar{\rho}_{\mathrm{o}} \lambda_{\mathrm{o}}\right)_{i j+1 / 2}^{n+1} \gamma_{i j}\left[\Phi_{\mathrm{o} j}^{n+1}-\Phi_{\mathrm{o} i}^{n+1}\right]+Q_{\mathrm{o} i}^{n+1}
$$

Water phase:

$$
\left\{\left[\varphi S_{\mathrm{w}} \rho_{\mathrm{w}}\right]_{i}^{n+1}-\left[\varphi S_{\mathrm{w}} \rho_{\mathrm{w}}\right]_{i}^{n}\right\} \frac{V_{i}}{\Delta t}=\sum_{j \in \eta_{i}}\left(\rho_{\mathrm{w}} \lambda_{\mathrm{w}}\right)_{i j+1 / 2}^{n+1} \gamma_{i j}\left[\Phi_{\mathrm{w} j}^{n+1}-\Phi_{\mathrm{w} i}^{n+1}\right]+Q_{\mathrm{w} i}^{n+1}
$$

Gas phase:

$$
\begin{gathered}
\left\{\left[S_{\mathrm{o}} \bar{\rho}_{\mathrm{dg}}+\varphi S_{\mathrm{g}} \rho_{\mathrm{g}}\right]_{i}^{n+1}-\left[S_{\mathrm{o}} \bar{\rho}_{\mathrm{dg}}+\varphi S_{\mathrm{g}} \rho_{\mathrm{g}}\right]_{i}^{n}\right\} \frac{V_{i}}{\Delta t}=\sum_{j \in \eta_{i}}\left(\bar{\rho}_{\mathrm{dg}} \lambda_{\mathrm{o}}\right)_{i j+1 / 2}^{n+1} \gamma_{i j}\left[\Phi_{\mathrm{o} j}^{n+1}-\Phi_{\mathrm{o} i}^{n+1}\right]+ \\
\sum_{j \in \eta_{i}}\left(\rho_{\mathrm{g}} \lambda_{\mathrm{g}}\right)_{i j+1 / 2}^{n+1} \gamma_{i j}\left[\Phi_{\mathrm{g} j}^{n+1}-\Phi_{\mathrm{g} i}^{n+1}\right]+Q_{\mathrm{g} i}^{n+1}
\end{gathered}
$$

Where: $n$ is the last time point; $n+1$ is the current time point; $V$ is the volume of grid block; $\Delta t$ is the length of the time step; $\eta_{\mathrm{i}}$ is the set of node $j$ or the nodes that are connected with node $i ; i j+1 / 2$ is the reasonable intermediate point between node $i$ and $j ; \lambda_{1}$ is the mobility of $l$ 
phase, $\lambda_{l}=\frac{k_{r l}}{\mu_{l}}, 10^{-3} \mu \mathrm{m}^{2} / \mathrm{mPa} \cdot \mathrm{s} ; \gamma_{\mathrm{ij}}$ is the transfer coefficient, $\gamma_{i j}=\frac{A_{i j} k_{i j+1 / 2}}{d_{i}+d_{j}}, 10^{-3} \mu \mathrm{m}^{2} \cdot \mathrm{m}$; $\Phi_{l i}^{n+1}$ is the gradient of pressure for $l$ phase, $\Phi_{l i}^{n+1}=P_{l i}^{n+1}-\rho_{l, i j+1 / 2}^{n+1} g D_{i}-G_{i}, \mathrm{MPa} / \mathrm{m} ; A_{\mathrm{ij}}$ is the common surface area between node $i$ and $j ; \mathrm{d}_{\mathrm{i}}$ is the distance between the center of node $i$ and the common surface of node $i$ and $j ; \mathrm{d}_{\mathrm{j}}$ is the distance between the center of node $j$ and the common surface of node $i$ and $j ; \mathrm{k}_{\mathrm{ij}+1 / 2}$ is the average absolute permeability of the connecting areas of node $i$ and $j ; \mathrm{D}_{\mathrm{i}}$ is the depth of the center of node $i ; Q_{l i}^{n+1}$ is the mass generation rate of the $l$ phase, $Q_{l i}^{n+1}=q_{l i}^{n+1} V_{i}$.

Equations (51), (52), and (53) can be written in the following remainder form.

$$
\begin{gathered}
R_{i}^{o, n+1}=\left\{\left[\varphi S_{\mathrm{o}} \bar{\rho}_{\mathrm{o}}\right]_{i}^{n+1}-\left[\varphi S_{\mathrm{o}} \bar{\rho}_{\mathrm{o}}\right]_{i}^{n}\right\} \frac{V_{i}}{\Delta t}-\sum_{j \in \eta_{i}}\left(\bar{\rho}_{\mathrm{o}} \lambda_{\mathrm{o}}\right)_{i j+1 / 2}^{m} \gamma_{i j}\left[\Phi_{\mathrm{o} j}^{n+1}-\Phi_{\mathrm{o} i}^{n+1}\right]-Q_{\mathrm{o} i}^{n+1} \\
R_{i}^{\mathrm{w}, n+1}=\left\{\left[\varphi S_{\beta} \rho_{\mathrm{w}}\right]_{i}^{n+1}-\left[\varphi S_{\mathrm{w}} \rho_{\mathrm{w}}\right]_{i}^{n}\right\} \frac{V_{i}}{\Delta t}-\sum_{j \in \eta_{i}}\left(\rho_{\mathrm{w}} \lambda_{\mathrm{w}}\right)_{i j+1 / 2}^{m} \gamma_{i j}\left[\Phi_{\mathrm{w} j}^{n+1}-\Phi_{\mathrm{w} i}^{n+1}\right]-Q_{\mathrm{w} i}^{n+1} \\
R_{i}^{g, n+1}=\left\{\left[\varphi S_{\mathrm{o}} \bar{\rho}_{\mathrm{dg}}+\varphi S_{\mathrm{g}} \rho_{\mathrm{g}}\right]_{i}^{n+1}-\left[\varphi S_{\mathrm{o}} \bar{\rho}_{\mathrm{dg}}+\varphi S_{\mathrm{g}} \rho_{\mathrm{g}}\right]_{i}^{n}\right\} \frac{V_{i}}{\Delta t} \\
-\sum_{j \in \eta_{i}}\left(\bar{\rho}_{\mathrm{dg}} \lambda_{\mathrm{o}}\right)_{i j+1 / 2}^{m} \gamma_{i j}\left[\Phi_{\mathrm{o} j}^{n+1}-\Phi_{\mathrm{o} i}^{n+1}\right]-\sum_{j \in \eta_{i}}\left(\rho_{\mathrm{g}} \lambda_{\mathrm{g}}\right)_{i j+1 / 2}^{m} \gamma_{i j}\left[\Phi_{\mathrm{g} j}^{n+1}-\Phi_{\mathrm{g} i}^{n+1}\right]-Q_{\mathrm{g} i}^{n+1}
\end{gathered}
$$

Where $i=1,2,3, \ldots, \mathrm{N}, m$ is either $n$ or $n+1$, which is decided by whether the equation is using an implicit method in pressure equations and explicit method in saturation equations or a fully implicit method, and $\mathrm{N}$ is the total number of nodes.

Newton-Raphson's iterative method is used to solve equations (54) to (56), which expands to $3 \mathrm{~N}$ coupled nonlinear equations including the three mass balance equations for gas, water, and oil phase, respectively, at each node. As shown in Table 1, there are three main variables at each node: the oil pressure, the oil phase saturation, and the saturation pressure (or vapor pressure). The main variables chosen in the software are similar to those in the black oil reservoir simulation software. An automatic variable transformation system is used to resolve the generation and depletion of the free gas in the numerical simulation of the three phases.

Table 1. The selection of the main variables with the relating equations

\begin{tabular}{|c|c|c|}
\hline Equation & Main variable & Physical meaning \\
\hline Oil phase & $\mathrm{x}_{1}=P_{\mathrm{o}}$ & Oil phase pressure \\
\hline Water phase & $\mathrm{x}_{2}=S_{\mathrm{o}}$ & Oil saturation \\
\hline Gas phase & $\mathrm{x}_{3}=P_{\mathrm{s}}$ or $\mathrm{x}_{3}=S_{\mathrm{g}}$ & $\begin{array}{c}\text { Saturation pressure or gas } \\
\text { saturation }\end{array}$ \\
\hline
\end{tabular}

Table 1 indicates that the first two of the main variables are fixed. The choice of the third one depends on the phase conditions of the current node. If there is no free gas, the node is then considered to be at an unsaturated condition (or its pressure is above the bubble point pressure) and the saturation pressure is the third main variable. If free gas exists, then the node is considered to be saturated (or its pressure is below the bubble point pressure). In this case, the gas saturation is the third main variable. The variable transformation system is 
accurate and highly efficient when it comes to changing bubble point problems in the numerical simulation of the reservoir. The numerical results show that when solving the three-phase problem using the nonlinear iterative method, different numerical performances can be observed for difference selections of main variables. The best combination of the main variables is to choose. When solving phase transition problems with different porosities or different phase conditions.

The Newton-Raphson's method for the three main variables gives [4]:

$$
R_{i}^{l, n+1}\left(x_{k, p+1}\right)=R_{i}^{l, n+1}\left(x_{k, p}\right)+\sum_{k} \frac{\partial R_{i}^{l, n+1}\left(x_{k, p}\right)}{\partial x_{k}}\left[x_{k, p+1}-x_{k, p}\right]=0
$$

Where $p$ is the number of iterations.

Equation (57) can be written as:

$$
\sum_{k} \frac{\partial R_{i}^{l, n+1}\left(x_{k, p}\right)}{\partial x_{k}}\left(\delta x_{k, p+1}\right)=-R_{i}^{l, n+1}\left(x_{k, p}\right)
$$

Where $i=1,2,3, \ldots, \mathrm{N} ; k=1,2,3 ; \delta x_{k, p+1}$ is the increments of the main variables between successive iterations.

Equation (58) represents a system of $3 \mathrm{~N}$ linear equations.

Numerical method is used to construct the Jacobian of Equation (58). For nodes with fully implicit formulation, the Jacobian can be calculated by numerical differentiation methods. For nodes with implicit pressure equations and explicit saturation equations, an easier semianalytic method can be used to calculate the Jacobian.

For a three-phase flow problem, the Jacobian of the linear system (58) is a nonsymmetrical matrix. Modern sparse matrix techniques are used to solve this problem in the proposed software. A modified sparse matrix algorithm is applied in the software as the solution algorithm of linear equations. The algorithm is based on the incomplete LU factorization method and CG type acceleration system [5]. The stability and efficiency of this numerical algorithm have been confirmed in multiple theoretical studies and practical applications.

\section{Boundary Conditions and Well Treatments}

The treatments of boundary conditions and wells are the biggest obstacle when programming a multi-phase numerical simulation software. The difficulty comes from the characteristics of the multi-phase flow PDE. In general, these kinds of PDE are parabolichyperbolic. The main variables and mass flow rates tend to have drastic changes at the well nodes and the boundaries [6]. Therefore, the nodes at the boundaries are special and are the hardest ones to converge in the simulation.

Moreover, the interferences between the phases at the boundaries make it hard to describe the boundary conditions of multi-phase flows. The pressure of a phase at the boundaries should be the same as the pressures of other phases at the same location. The pressures of the phases are also related to the capillary forces. In most cases, flows in only one of two phases need to be described at the boundaries. It is valuable to know whether there is inlet or outlet flows at a given node for certain phase, but in most cases, it is impossible. Therefore, it is important to give descriptions of the conditions of flows which match the real conditions. 
A variety of multi-phase flow boundary condition problems are studied in the program. Strictly speaking, boundary conditions are only restriction constraints when describing the multi-phase flows [7]. More generally, they are mathematical conditions that are needed for solving PDE. The results from $\mathrm{Wu}$ et al., are applied in the proposed software to treat the boundary conditions. The method is general and matches well with real life conditions. This method regards all kinds of boundary conditions as real point sinks or point sources. Within a time step, the mass of the boundary points either increases or decreases. Numerically, fully implicit method is often used for the boundary grid, but in some cases, implicit method for pressure equations and explicit method for saturation equations. This source/sink method is suitable for all kinds of boundary conditions that may be encountered in the numerical simulations that involve the generation of multi-phase flows.

In terms of concision, it is very convenient to use the large volume method $\left(V_{i}=10^{50} \mathrm{~m}^{3}\right)$ to treat the Dirichlet boundary condition, i.e., the first-type boundary condition, in the software. The treatment of different types of wells discussed below is suitable for all types of boundary conditions. Additionally, it should be pointed out that in the software, both grid points that are next to the boundary and on the boundary can be regarded as boundary gird points. If boundary conditions are not defined, sealed boundaries are assumed.

\subsection{The first-type boundary condition}

The first-type boundary conditions are constant phase pressures and constant saturation conditions in the software. This kind of boundary condition can be treated by the large volume method. The method assumes that a node that has constant pressure and constant saturation condition has a very large volume without changing any geometric parameters in the grid. However, the phase conditions of the boundary grids and the differentiation between nodes for the injection wells and those for the production wells should be carefully treated in the method. Once everything is defined, the main variables of the boundary nodes can be identified. The software treats these nodes the same way as the other nodes. The inlet and outlet flows of these boundary nodes with large volume are obtained by the Darcy's Law, too. In order to get a correct result from the large volume method, the inlet and outlet flows should match the real life situations.

\subsection{Convectional boundary conditions}

Whether to use sink and source terms to treat the convectional-type boundary conditions depends on the production and injection conditions, which can be added to the mass balance equations (54) to (56). This method is especially suitable for cases where the flow allocation at the boundary is known, for example, water intrusion. The method is also suitable for injection or production wells that are only connected to a single grid block and whose injection or production pressure needs not to be considered. However, the method does not suit for wells that go through multiple oil layers or reservoirs.

\subsection{The treatment of wells}

The virtual node method is used for well boundary conditions. The method regards a borehole as a single or multiple computation nodes that are connected to surrounding nodes. The borehole can be a vertical well, an inclined well, or a horizontal well [8]. The treatment of the borehole nodes is identical to that of other nodes. Production and injection conditions are defined by the point sink or point source coefficients associated with constant pressure or constant flow rate conditions. Generally speaking, mass balance equations still hold for well node $i$. In the software, it is assumed that there is no other boundary condition for a well node 
except for suction or injection action. Therefore, Equation (54) to (56) for well node $i$ can be rewritten as:

$$
\begin{gathered}
R_{i}^{\mathrm{o}, n+1}=\left\{\left[\phi S_{\mathrm{o}} \bar{\rho}_{\mathrm{o}}\right]_{i}^{n+1}-\left[\phi S_{\mathrm{o}} \bar{\rho}_{\mathrm{o}}\right]_{i}^{n}\right\} \frac{V_{i}}{\Delta t}-\sum_{j \in \eta_{i}}\left(\bar{\rho}_{\mathrm{o}} \lambda_{\mathrm{o}}\right)_{i j+1 / 2}^{m} P I_{i j}\left[\Phi_{\mathrm{o} j}^{n+1}-\Phi_{\mathrm{o} i}^{n+1}\right]-Q_{\mathrm{o}, \mathrm{w}}^{n+1} \\
R_{i}^{\mathrm{w}, n+1}=\left\{\left[\phi S_{l} \rho_{\mathrm{w}}\right]_{i}^{n+1}-\left[\phi S_{\mathrm{w}} \rho_{\mathrm{w}}\right]_{i}^{n}\right\} \frac{V_{i}}{\Delta t}-Q_{\mathrm{w}, \mathrm{w}}^{n+1}-\sum_{j \in \eta_{i}}\left(\rho_{\mathrm{w}} \lambda_{\mathrm{w}}\right)_{i j+1 / 2}^{m} P I_{i j}\left[\Phi_{\mathrm{w} j}^{n+1}-\Phi_{\mathrm{w} i}^{n+1}\right] \\
R_{i}^{\mathrm{g}, n+1}=\left\{\left[\phi S_{\mathrm{o}} \bar{\rho}_{\mathrm{dg}}+\phi S_{\mathrm{g}} \rho_{\mathrm{g}}\right]_{i}^{n+1}-\left[\phi S_{\mathrm{o}} \bar{\rho}_{\mathrm{dg}}+\phi S_{\mathrm{g}} \rho_{\mathrm{g}}\right]_{i}^{n}\right\} \frac{V_{i}}{\Delta t}-Q_{\mathrm{g}, \mathrm{w}}^{n+1} \\
-\sum_{j \in \eta_{i}}\left(\bar{\rho}_{\mathrm{dg}} \lambda_{\mathrm{o}}\right)_{i j+1 / 2}^{n+1} P I_{i j}\left[\Phi_{\mathrm{o} j}^{n+1}-\Phi_{\mathrm{o} i}^{n+1}\right]-\sum_{j \in \eta_{i}}\left(\rho_{\mathrm{g}} \lambda_{\mathrm{g}}\right)_{i j+1 / 2}^{n} P I_{i j}\left[\Phi_{\mathrm{g} j}^{n+1}-\Phi_{\mathrm{g} i}^{n+1}\right]
\end{gathered}
$$

Where $P I_{\mathrm{ij}}$ is the production or injection index between well node $i$ and its adjacent node $j$.

There are many ways to calculate the well index in the petroleum industry. For a vertical borehole, the index defined by the following equation:

$$
P I_{i j}=\frac{2 \pi k \Delta z_{j}}{\ln \left(\frac{r_{\mathrm{e}}}{r_{\mathrm{w}}}\right)+s-1 / 2}
$$

Where $\Delta z_{j}$ is the effective thickness of the layer $j, \mathrm{~m} ; r_{\mathrm{e}}$ is the effective radius of the grid node, $\mathrm{m} ; S$ is the skin factor.

The injection rate for an injection well is:

$$
Q_{l, \mathrm{w}}=\sum_{j \in \eta_{i}}\left(\rho_{l} \lambda_{l}\right)_{i j+1 / 2} P I_{i j}\left[P_{l, j}-P_{\mathrm{w}}-\rho_{l} \mathrm{~g}\left(D_{j}-D_{\mathrm{w}}\right)\right]
$$

The production rate for a production well is:

Oil phase:

$$
Q_{\mathrm{o}, \mathrm{w}}=\sum_{j \in \eta_{i}}\left(\bar{\rho}_{\mathrm{o}} \lambda_{\mathrm{o}}\right)_{i j+1 / 2} P I_{i j}\left[P_{\mathrm{o}, j}-P_{\mathrm{w}}-\rho_{\mathrm{o}} g\left(D_{j}-D_{\mathrm{w}}\right)\right]
$$

Water phase:

$$
Q_{\mathrm{w}, \mathrm{w}}=\sum_{j \in \eta_{i}}\left(\rho_{\mathrm{w}} \lambda_{\mathrm{w}}\right)_{i j+1 / 2} P I_{i j}\left[P_{\mathrm{w}, j}-P_{\mathrm{w}}-\rho_{\mathrm{w}} g\left(D_{j}-D_{\mathrm{w}}\right)\right]
$$

Gas phase:

$$
\begin{aligned}
Q_{\mathrm{g}, \mathrm{w}}= & \sum_{j \in \eta_{i}}\left(\rho_{\mathrm{g}} \lambda_{\mathrm{g}}\right)_{i j+1 / 2} P I_{i j}\left[P_{\mathrm{g}, j}-P_{\mathrm{w}}-\rho_{\mathrm{g}} g\left(D_{j}-D_{\mathrm{w}}\right)\right] \\
& +\sum_{j \in \eta_{i}}\left(\bar{\rho}_{\mathrm{dg}} \lambda_{\mathrm{o}}\right)_{i j+1 / 2} P I_{i j}\left[P_{\mathrm{o}, j}-P_{\mathrm{w}}-\rho_{\mathrm{o}} g\left(D_{j}-D_{\mathrm{w}}\right)\right]
\end{aligned}
$$


In the above equations, the summation of the flow terms between node $i$ and its adjacent node $j$ is the total mass flow rate. $P_{\mathrm{w}}$ is the bottom-hole pressure, which is determined in the next section. $D_{\mathrm{w}}$ is the depth of the pump in the borehole.

The transmissibility in Equation (59) to (61) and (63) to (66) can be calculated by a weighted average of the upstream values. Moreover, besides the source and sink terms in equation (63) and (66), the well nodes are treated as virtual nodes as other nodes.

When using the virtual node method, the rock characteristic parameters of the virtual nodes should be defined. The capillary pressure and relative permeability functions should be defined for all the well nodes. Since the well nodes are considered to be normal nodes when solving the equations, all the flow characteristics and relative structural relations are needed for well nodes.

4.3.1. Constant rate production well: There are two cases in general, (a) fixed total production rate, and (b) fixed production rate of one of the phases (including the production of oil, gas, or water phase). The ways to solve these two cases are different. The method shown below not only is accurate and highly efficient for production wells, but also allows back flow, which is hard to solve for other software.

1) Fixed total production rate

In this case, the bottom-hole flowing pressure is:

$$
\begin{aligned}
P_{\mathrm{w}}= & \left\{-Q_{L}+\sum_{j \in \eta_{i}} \sum_{\beta}\left(\rho_{l} \lambda_{l} / \rho_{l}^{\mathrm{o}}\right)_{i j+1 / 2} P I_{i j}\left[P_{l, j}-\rho_{l} \mathrm{~g}\left(D_{j}-D_{\mathrm{w}}\right)\right]\right\} \\
& \div\left\{\sum_{j \in \eta_{i}} \sum_{l}\left(\rho_{l} \lambda_{l} / \rho_{l}^{\mathrm{o}}\right)_{i j+1 / 2} P I_{i j}\right\}
\end{aligned}
$$

The bottom-hole pressure defined by Equation (67) should satisfy the constraint:

$$
P_{\mathrm{w}} \geq P_{\mathrm{w}, \min }
$$

Where $P_{\mathrm{w}, \mathrm{min}}$ is the minimum pressure allowed in the well. Equation (68) ensures that wells do not function for all user-specified production rates. If this constraint does not hold, the production of the well goes under constant pressure.

The productions for all phases are calculated by Equation (64) to (66). The pressure is determined by Equation (67) and (68). Although the flow rate of the fluid is defined, there will also be gas phase in the well. The production of gas phase is calculated by Equation (66). The corresponding bottom-hole pressure is also determined by Equation (67) and (68). If the solution converges to zero capillary pressure, the bottom-hole pressure $P_{\mathrm{w}}$ should be close to the node pressure $P_{i}$ from the simulation.

2) Fixed single phase flow production rate

The pressure in this case is:

$$
P_{\mathrm{w}}=\left\{-\rho_{l, \mathrm{STC}} Q_{\mathrm{o}}+\sum_{j \in \eta_{i}}\left(\rho_{l} \lambda_{l}\right)_{i j+1 / 2} P I_{i j}\left[P_{l, j}-\rho_{l} \mathrm{~g}\left(D_{j}-D_{\mathrm{w}}\right)\right]\right\} \div\left\{\sum_{j \in \eta_{i}}\left(\rho_{l} \lambda_{\mathrm{o}}\right)_{i j+1 / 2} P I_{i j}\right\}
$$

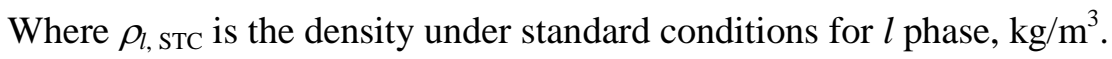


The pressure in Equation (69) should also satisfy constraint (68). The production rates are calculated by Equation (64) to (66). The results are substituted in Equation (59) to (61). The production rate for other phases is calculated according to the same bottom-hole pressure.

4.3.2. Production wells with constant pressure: If the production of a well is under some constant pressure, then the pressure can be used directly in Equation (59) to (61). In this case, multiple or all of the phases will be produced. This depends on the formation conditions of nodes adjacent to the well. In the software, the three point sinks for three phases are calculated by Equation (64) to (66), and then plugged into equation (59) to (61).

4.3.3. Injection well with constant flow rate: The injection rate for an injection well is known. The injected phase can be oil, gas, or water. Back flows are not allowed in this case. The injection pressure for an injection well with constant mass injection rate is:

$$
P_{\mathrm{w}}=\left\{Q_{l}+\sum_{j \in \eta_{i}}\left(\rho_{l} \lambda_{l}\right)_{i j+1 / 2} P I_{i j}\left[P_{l, j}-\rho_{l} g\left(D_{j}-D_{\mathrm{w}}\right)\right]\right\} \div\left\{\sum_{j \in \eta_{i}}\left(\rho_{l} \lambda_{l}\right)_{i j+1 / 2} P I_{i j}\right\}
$$

The injection pressure satisfies the constraint:

$$
P_{\mathrm{w}} \leq P_{\mathrm{w}, \max }
$$

Where $P_{\mathrm{w}, \max }$ is the maximum allowed injection pressure. When the injection pressure of the well is larger than $P_{\mathrm{w}, \max }$, the well injects under constant pressure.

The injection rate is calculated by Equation (63). The injection pressure is calculated by Equation (70) and (71). The results are used in Equation (59) to (61) for node $i$.

4.3.4 Injection well with constant pressure: Water is injected under constant pressure. The injection pressure can be substituted into Equation (63) to find the injection rate. If the well is single layer injection wells, this injection condition can be treated by the large volume method. However, for multiple layer injection wells, the injection rates for phases are determined and allocated by Equation (63). Equation (59) to (61) is then used for solutions.

4.3.5 Special considerations for treatments of well conditions: The virtual node method is flexible and efficient. Compared to traditional potential and flow allocation method, the advantages of the virtual node method are that it considers the back flow phenomena and reflects the impact of the adjacent nodes on the well phase to the Jacobian matrix [9]. The stability of the total Jacobian matrix and the full implicit calculation using this method when solving multi-layer problems is good.

However, due to the fact that boreholes have small volume and high flow rate, there will be numerical difficulties when performing the Newton iterations [10]. The trick to solve this problem is to multiply a coefficient between 100 and 1000 to the variable. This trick increases the wellbore storage effect and reduces the oscillations in the Newton's iteration. The simulation results show that the wellbore storage effect has little effect on the convergence. Therefore, it is recommended that for constant flow rate production and injection wells, the wellbore storage method should be considered, while for constant pressure production and injection problems, the infinite large volume method gives a better performance. 


\section{Programming}

A 3D three-phase non Darcy flow numerical simulation software is programmed according to the solution of the non-Darcy flow mathematical model. The program flowchart is shown in Figure 1. The software can simulate the oil reservoir water displacement development dynamic index. It solves the problems even when the effective thickness, porosity, or permeability is zero, which often is an obstacle for numerical simulations. Meanwhile, in order to reduce the time to prepare parameters and process simulation results, a pre and post processing system is programmed to facilitate the loading and editing of parameters as well as the presentation of figures for the simulation results. The main programming of the numerical simulation uses FORTAN99 language, taking advantage of its high speed for large scale engineering calculations. The programming of the pre and post process system uses DELPHI language. The language has a decent interface under WINDOWS and has the ability to manage databases.

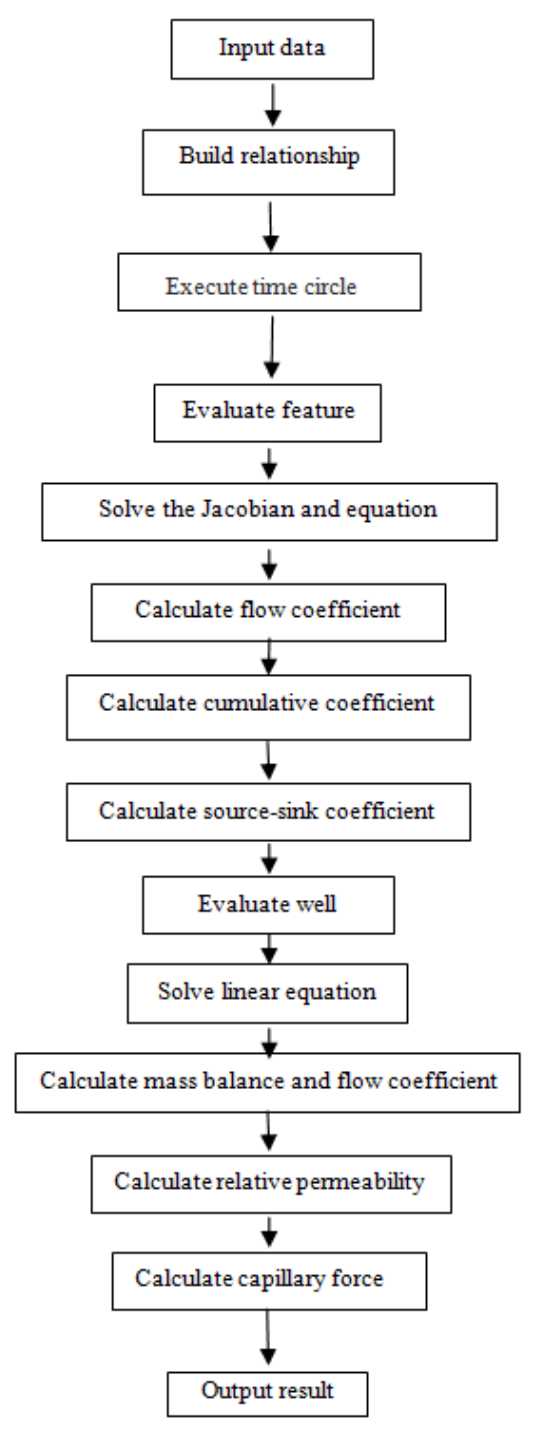

Figure 1. Flow chart of main program 


\section{Non-Darcy Flow Numerical Simulation Application for Low Permeability Oilfields}

\subsection{The impact of threshold pressure gradient on the development}

According to the results from indoor laboratory study, the threshold pressure gradient and the permeability in YuShuLin have a power function relation. With the decrease in the permeability, the threshold pressure gradient increases and the sweep efficiency gradually decreases. In order to have a quantitative study on the impact of the threshold pressure gradient on the performance of oilfield development, numerical simulations where the threshold pressure gradient is considered were done using the proposed software. A uniform distributed mass model is adopted. The surface is discretized by a $30 \times 30$ uniform gird with a grid length of $20 \mathrm{~m}$. The inversed nine spot water injection pattern is used. The well spacing is $300 \mathrm{~m}$. Major parameters for the oil reservoir are shown in Table 2. The sweep efficiency and recovery were calculated for cases where permeability is $1 \times 10^{-3} \mu \mathrm{m}^{2}$ to $12 \times 10^{-3} \mu \mathrm{m}^{2}$ and the water cut is $98 \%$. The results are shown in Figure 2. Results from cases with different permeability and different pressures and saturations of corresponding water cuts are shown in Figure 3, 4, and 5.

Table 2. Reservoir parameters used in the model

\begin{tabular}{|c|c|c|c|c|c|}
\hline Porosity (\%) & $\begin{array}{c}\text { Oil saturation } \\
(\%)\end{array}$ & $\begin{array}{c}\text { Volume } \\
\text { factor }\end{array}$ & $\begin{array}{c}\text { Original } \\
\text { formation } \\
\text { pressure } \\
(\mathrm{MPa})\end{array}$ & $\begin{array}{c}\text { Water } \\
\text { injection well } \\
\text { pressure } \\
(\mathrm{MPa})\end{array}$ & $\begin{array}{c}\text { Bottom-hole } \\
\text { pressure of oil } \\
\text { well } \\
(\mathrm{MPa})\end{array}$ \\
\hline 15.00 & 44.30 & 1.0967 & 18.50 & 24.00 & 3.00 \\
\hline
\end{tabular}

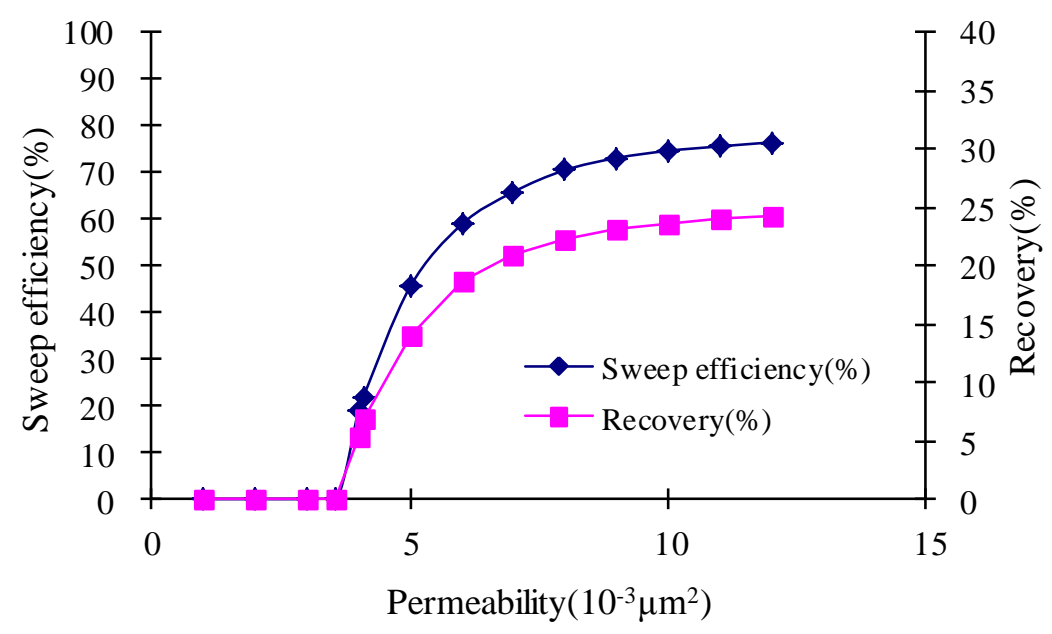

\section{Figure 2. Relation between permeability and sweep efficiency when well spacing is $300 \mathrm{~m}$}

It can be seen from the relation between the water cut and the sweep efficiency that the sweep efficiency increases with the increase of water cut. When the water cut reaches $98 \%$, the corresponding sweep efficiency is the one used to calculate the effective driving coefficient for low permeability oil reservoirs. 

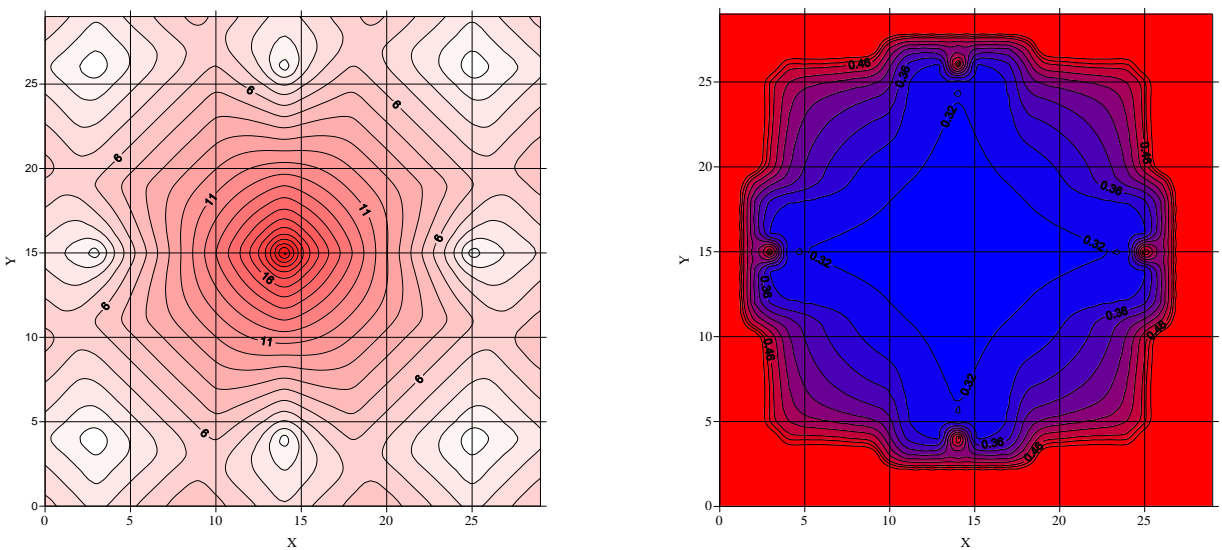

Figure 3. Pressure and saturation distribution when permeability is $4 \times 10-3 \mu \mathrm{m} 2$ and water cut is $98 \%$
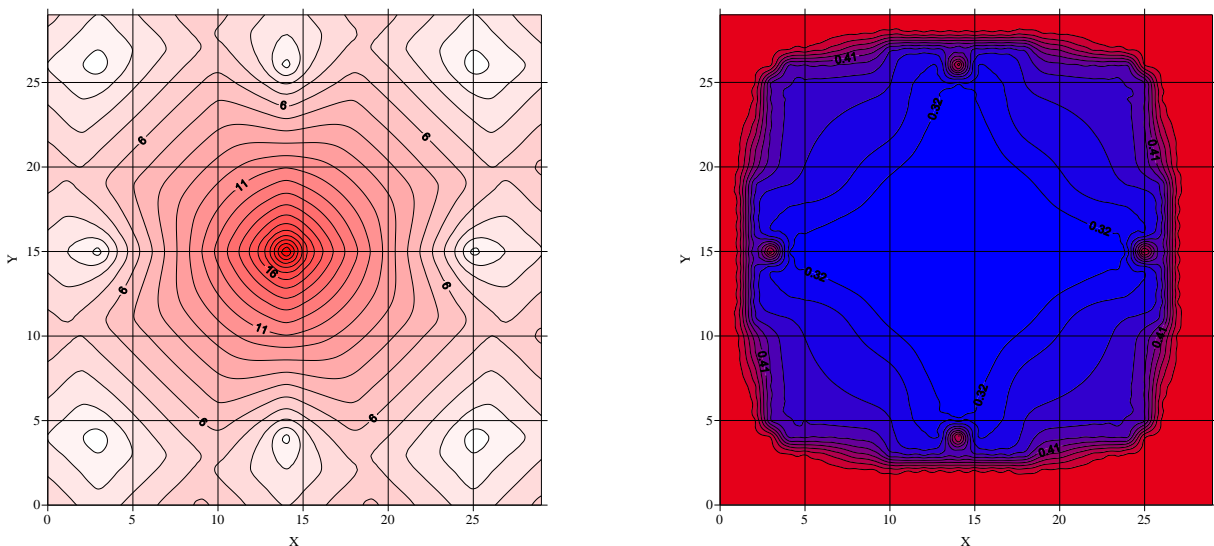

Figure 4. Pressure and saturation distribution when permeability is $5 \times 10-3 \mu \mathrm{m} 2$ and water cut is $98 \%$
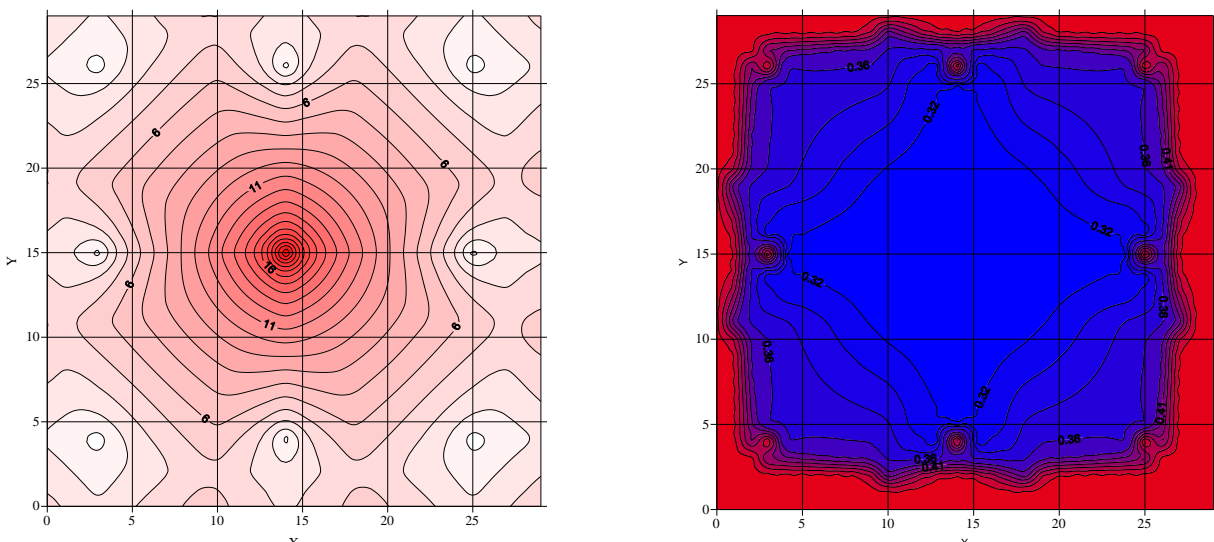

Figure 5. Pressure and saturation distribution when permeability is $12 \times 10-3 \mu \mathrm{m} 2$ and water cut is $98 \%$

Table 2 and Figure 4 to 6 show that the lower limit for the permeability to move the oil is $3.58 \times 10^{-3} \mu \mathrm{m}^{2}$ for $300 \mathrm{~m}$ well spacing. For permeability under $3.58 \times 10^{-3} \mu \mathrm{m}^{2}$, the crude oil in 
the reservoir cannot move. The sweep efficiency and the water displacement recovery are 0 . For permeability greater than $3.58 \times 10^{-3} \mu^{2}$, the threshold pressure gradient decreases with the increase of permeability. The sweep efficiency increases from $19 \%$ to $76.53 \%$. The water displacement recovery increases from $5.40 \%$ to $24.29 \%$.

\subsection{The impact of well spacing on the development performance}

It is crucial to choose a reasonable well spacing when developing a low permeability oilfield. In low permeability reservoirs, the flow resistance is large and the pressure transfer is weak [11]. If the spacing between water injection wells and oil production wells is large, it is hard for the water injection power to spread, which leads to a rapid increase in the water injection well pressure and builds up the pressure of surround areas of water injection wells. This will reduce the effective water injection pressure difference and finally decrease the amount of injected water. Water injection wells cannot absorb water efficiently, making it hard to satisfy the production requirements of the oilfields. As a result, the development of the oilfield will be encumbered by the low efficiency of water injection wells. Although by fracture reformation, the productivity index of low permeability oil wells increases, the low permeability characteristics of the entire reservoir has not been changes. The productivity index is still very low. Especially, when water is injected, by the double effects of the increase of water fraction and the decrease of fluid productivity index, the productivity index drastically decreases. This is an objective law.

The sweep efficiency and recovery for cases where the well spacing is $350 \mathrm{~m}, 300 \mathrm{~m}, 250 \mathrm{~m}$, $210 \mathrm{~m}$, and $150 \mathrm{~m}$ and the permeability varies from $1 \times 10^{-3} \mu \mathrm{m}^{2}$ to $12 \times 10^{-3} \mu \mathrm{m}^{2}$ were calculated in order to find the optimal well spacing that can establish an effective driving system under fixed permeability. Simulation results for cases with $98 \%$ water fraction are shown in Figure 6-7.

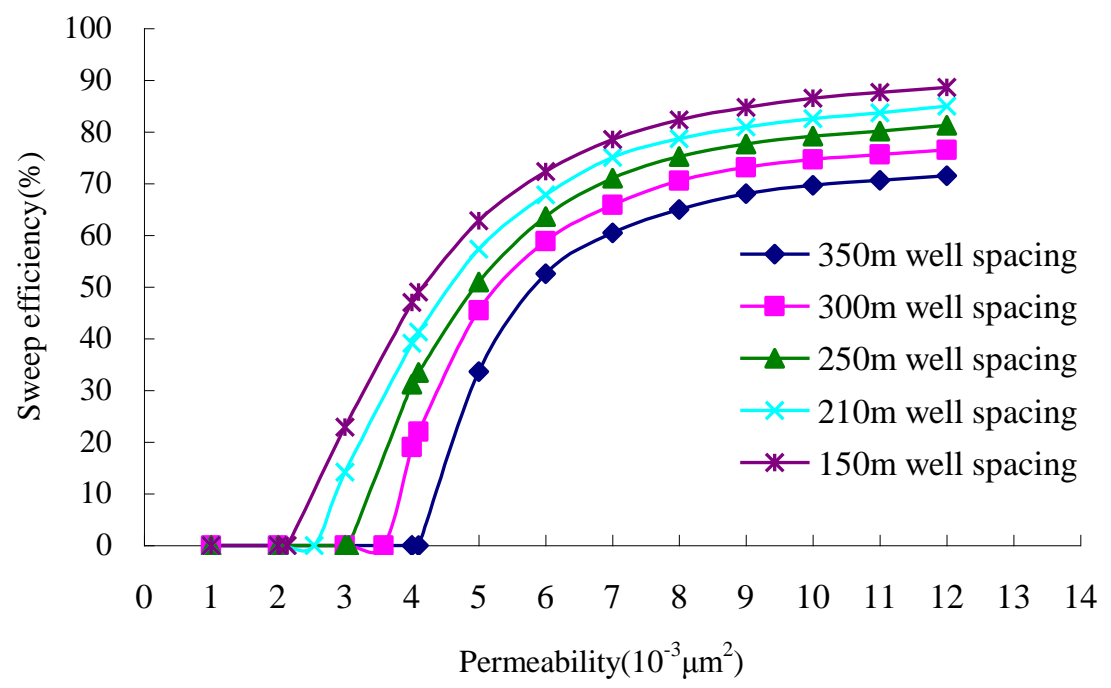

Figure 6. Relation curves between well spacing and sweep efficiency 


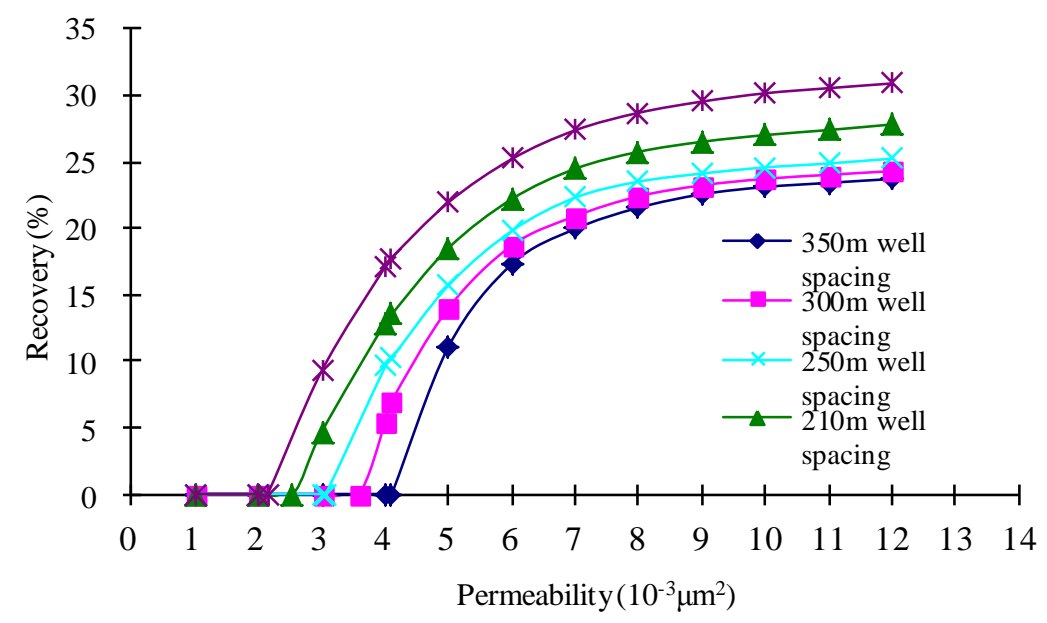

Figure 7. Relation curves between well spacing and recovery ratio
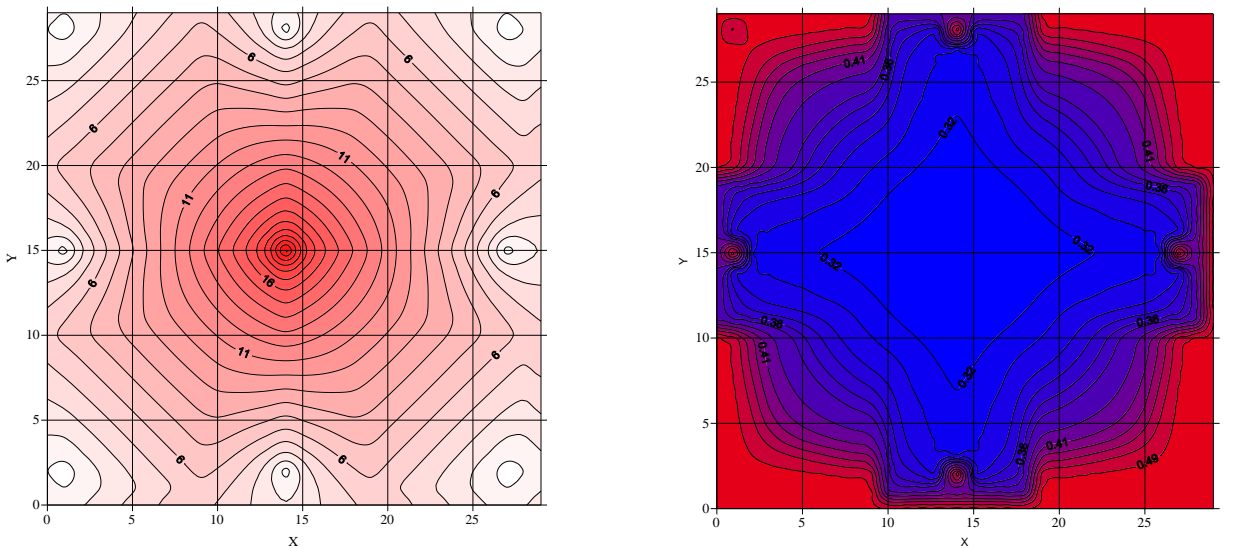

Figure 8. Pressure and saturation distribution when permeability is $5 \times 10-3 \mu \mathrm{m} 2$ and well spacing is $350 \mathrm{~m}$
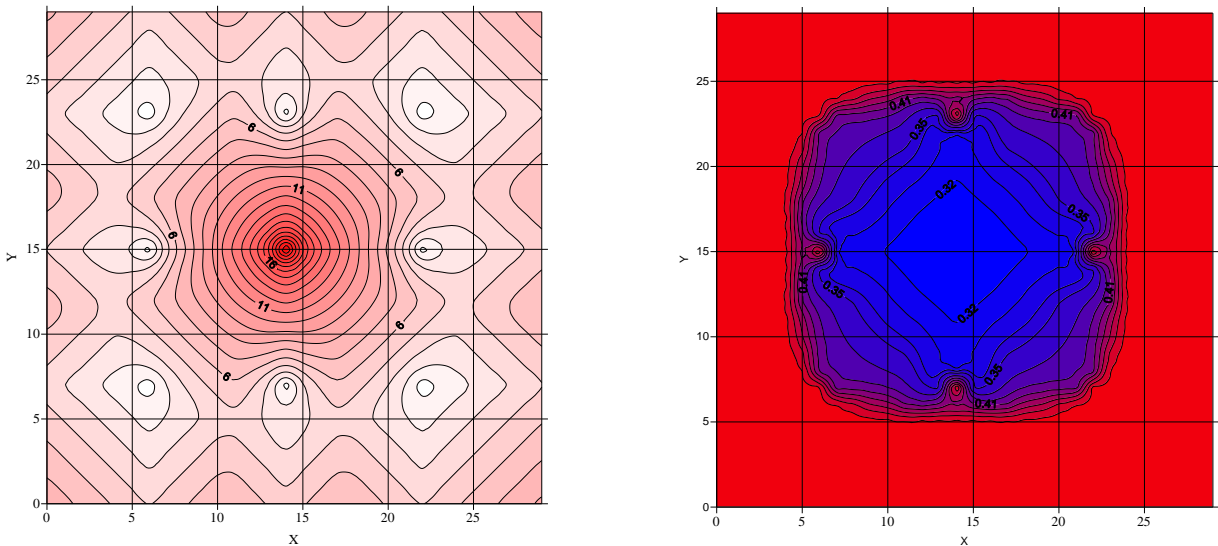

Figure 9. Pressure and saturation distribution when permeability is $5 \times 10-3 \mu \mathrm{m} 2$ and well spacing is $210 \mathrm{~m}$ 

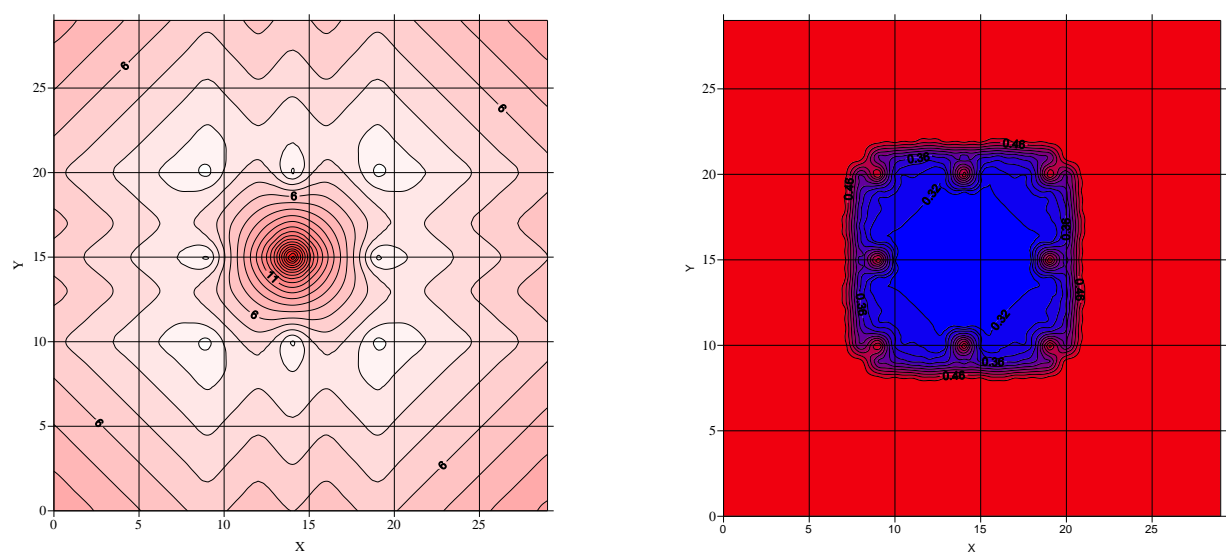

Figure 10. Pressure and saturation distribution when permeability is $5 \times 10$ $3 \mu \mathrm{m} 2$ and well spacing is $150 \mathrm{~m}$

It can be seen from the simulation results that with the decrease of well spacing, both of the sweep efficiency and recovery increase. When the permeability is $5 \times 10^{-3} \mu \mathrm{m}^{2}$, the sweep efficiency for $350 \mathrm{~m}$ well spacing is only $33.60 \%$. The recovery is only $11.10 \%$. Most of the areas in the reservoir are not swept. In order to establish an effective driving system, the well spacing is reduced to $150 \mathrm{~m}$. The sweep efficiency is now $62.80 \%$ and the recovery is $21.95 \%$. The reduction of well spacing can successfully overcome the threshold pressure gradient and improve the development performance of the oil reservoir. Therefore, when developing low permeability oilfields, a small well spacing should be used provided that the overall economic objective can be satisfied.

\subsection{The impact of water injection modes on the development performance}

Water injection mode is defined as the locations of water injection wells and the arrangement of water injection wells and oil production wells, which is the layout and the relative locations of water injection wells and oil production wells. The selection of water injection mode is mainly according to the development experiences of domestic and international oilfields and the formation characteristics of the oilfield. After chosen the water injection mode, the oilfield produces oil under this mode. The well grid and the distribution of the remaining oil will follow a specific pattern that is related to the water injection mode. These patterns affect the development of the entire oilfield. The development indices were calculated by the non-Darcy numerical simulation software for five-spot water injection mode, inversed nine-spot water injection pattern, and line water injection mode in order to study the impact of different water injection mode on the development performances.

The permeability used in the simulation is $5 \times 10^{-3} \mu \mathrm{m}^{2}$. The simulation results are shown in Table 3. The saturation and the pressure distributions are shown in Figure 11 to 13.

Table 3. Ultimate development index of different water injection mode

\begin{tabular}{|c|c|c|}
\hline Water injection mode & Sweep efficiency (\%) & Recovery (\%) \\
\hline $\begin{array}{c}\text { Inverted nine-spot water } \\
\text { flooding }\end{array}$ & 68.90 & 18.10 \\
\hline Line water flooding & 75.54 & 21.04 \\
\hline Five-spot water flooding & 76.68 & 21.67 \\
\hline
\end{tabular}



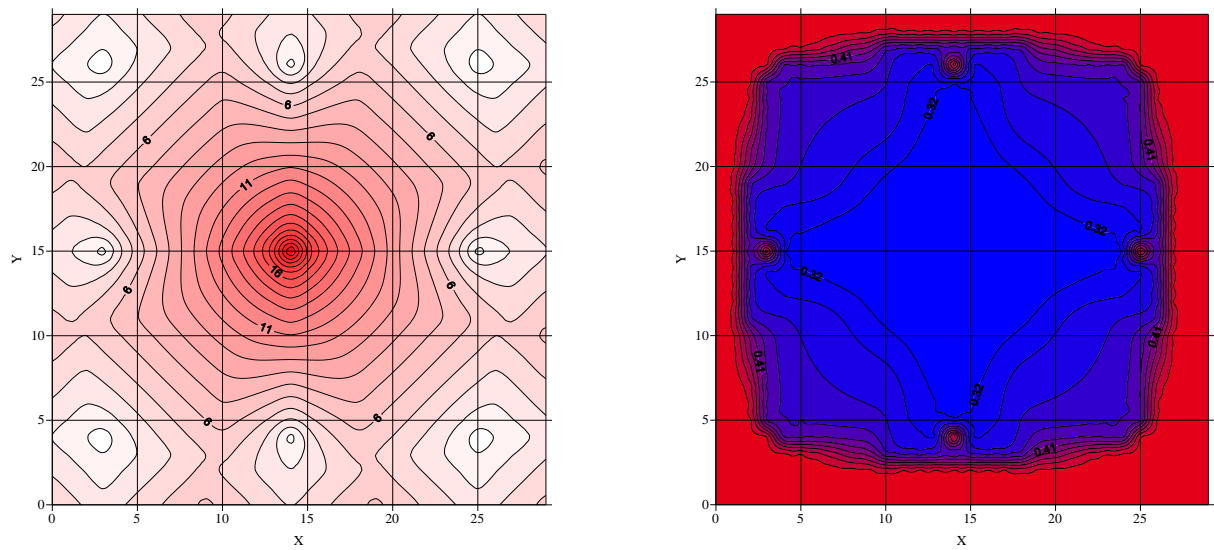

Figure 11. Pressure and saturation distribution of the inverted nine spot flooding pattern
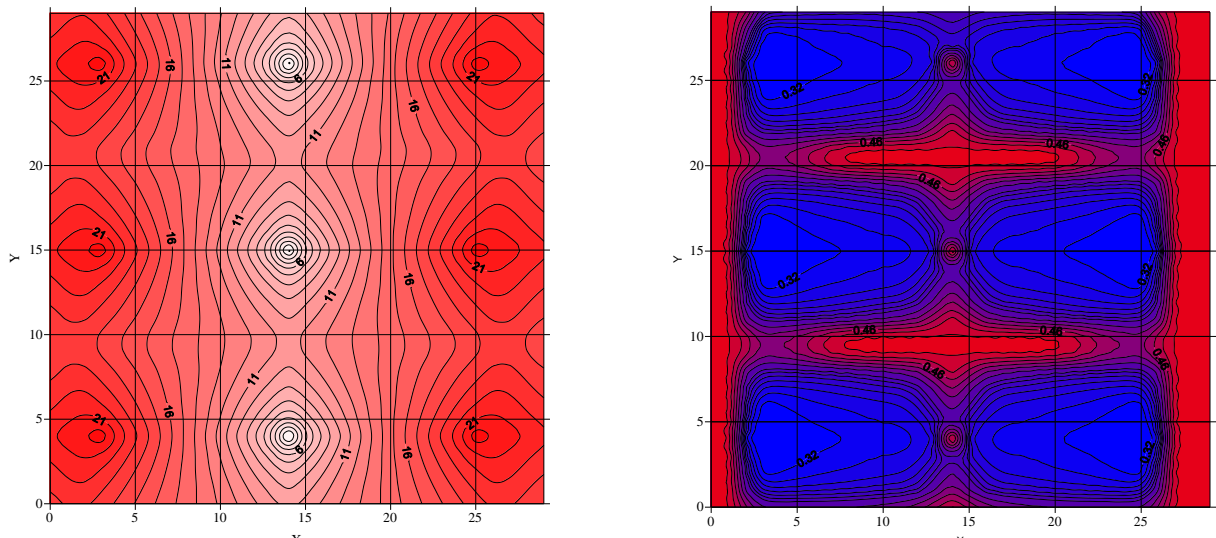

Figure 12. Pressure and saturation distribution of the line drive flooding pattern
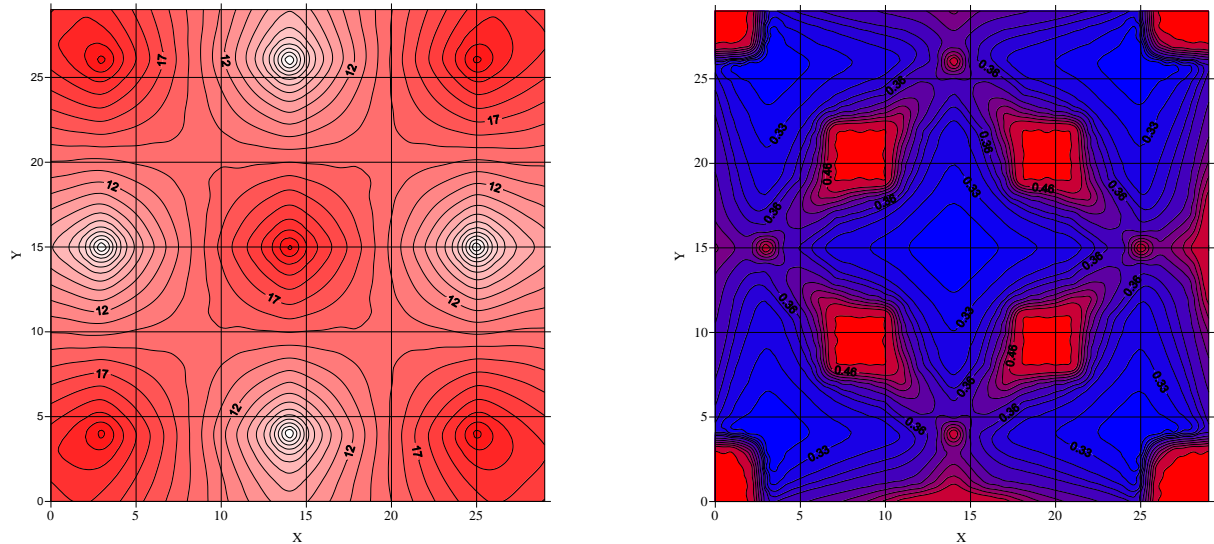

Figure 13. Pressure and saturation distribution of the five-spot water flooding pattern

It can be seen from the simulation results that the type of water injection mode has a big impact on the development performance. Compared with the inverted nine spot water 
injection pattern, the sweep efficiency of the line water injection mode and the five-spot water injection mode can be increased to $75.54 \%$ and $76.68 \%$, respectively. The recoveries of the latter two modes are increased to $21.04 \%$ and $21.67 \%$, respectively. The difference between the line water injection mode and the five-spot water injection mode is negligible. Therefore, for low permeability oilfields, besides an appropriate well gird density, a correct water injection mode has to be selected to have good sweep efficiency. The non-Darcy numerical simulation shows that the line injection mode and the five-spot water injection mode are more adaptive to low permeability oil reservoirs. They should be considered and associated with economic evaluations during the well pattern optimization process.

\section{Conclusions}

1. A mathematical model that describes the characteristics of non-Darcy flow was established using the non-Darcy flow theories. The correct treatment of the threshold pressure gradient for different underground flow directions was given. The numerical difference solutions were derived. A non-Darcy numerical simulation software was developed accordingly.

2. The non-Darcy numerical simulation results showed that when the permeability was increased from $1 \times 10^{-3} \mu \mathrm{m}^{2}$ to $12 \times 10^{-3} \mu^{2}$, the threshold pressure gradient decreased from $0.4481 \mathrm{MPa} / \mathrm{m}$ to $0.0377 \mathrm{MPa} / \mathrm{m}$. The sweep efficiency increased from 0 to $76.53 \%$. The water displacement recovery increased from 0 to $24.29 \%$. The effect of threshold pressure gradient on the sweep efficiency and water displacement recovery is remarkable.

3. For an oil reservoir with permeability of $5 \times 10^{-3} \mu \mathrm{m}^{2}$, when the well spacing was reduced from $350 \mathrm{~m}$ to $150 \mathrm{~m}$, the driving pressure gradient gradually increased. The sweep efficiency increased from $33.60 \%$ to $62.80 \%$ and the water displacement recovery increased from $11.10 \%$ to $21.95 \%$.

4. Compared with the inverted nine spot water injection mode, the sweep efficiencies of the line water injection mode and the five-spot water injection mode was increased by $6.64 \%$ and $7.78 \%$ respectively. The water displacement recovery was increased by $2.94 \%$ and $3.57 \%$.

\section{Acknowledgements}

This work is supported by the National Natural Science Foundation of China under Grant No.51074034.

\section{References}

[1] A. Vakil and J. D. Jansen, "On the Adjoint of a Nonlinear Diffusion-Convection Equation to Describe Flow in Porous Media", (2005) August 2-6; SPE Middle East Oil and Gas Show and Conference.

[2] R. Abdel-Ghani, "Single Porosity Simulation of Fractures With Low to Medium Fracture-to-Matrix Permeability Contrast”, (2009) February16-17; SPE/EAGE Reservoir Characterization and Simulation Conf.

[3] F. Gu, E Kuru, Z. Zhao and Z. Mo, "A Practical and Economical Fracturing Solution For Low Permeability Shallow Reservoirs", Journal of Canadian Petroleum Technology, vol. 5, (2003), pp. 42.

[4] D. O. Son, H. J. Choi, H. G. Jeon and C. H. Kim, "Thermal-aware 3D Multi-core Process-or Design using Core and Level-2 Cache Placement", International Journal of Control and Automation, vol. 6, (2013), pp. 25.

[5] X. P. Zhao and R. P. Young, "Numerical Simulation of Seismicity Induced by Hydraulic Fracturing in Naturally Fractured Reservoirs", (2009) March15-17; SPE Annual Technical Conference and Exhibition.

[6] R. D. Kokate and L. M. Waghmare, "Review of Tuning Methods of DMC and Performance Evaluation with PID Algorithms on a FOPDT Model”, International Journal of Control and Automation, vol. 4, (2011), pp. 95. 
[4] H. A. Belhaj, K. R. Agha, A. M. Nouri, S. D. Butt, H. F. Vaziri and M. R. Islam, "Num. Simulation of NonDarcy Flow Utilizing the New Forchheimer's Diffusivity Equation", (2003) May 7-9; Middle East Oil Show.

[8] Z. Xu, Y. Yin and J. Wang, "An Energy-efficient Clustering Algorithm in Wireless Sensor Networks with Multiple Sinks", International Journal of Control and Automation, vol. 5, (2012), pp. 131.

[9] H. Su and S. Aramco, "A Three-Phase Non-Darcy Flow Formulation in Reservoir Simulation", (2004) October 15-19; SPE Asia Pacific Oil and Gas Conference and Exhibition.

[10] Y. Kyung, J. -w. Kim, S. -B. Jung and K. -H. Eom, "Optimal Control Method for a Hydroelec-tric Power Development in Multi Level Dams", International Journal of Control and Automation, vol. 3, (2009), pp. 13.

[11] A. Fouad, D. Boukhetela and F. Boudjema, "Decentralized Sliding Mode Controller Based on Genetic algorithm and a Hybrid approach for Interconnected Uncertain Nonlinear Systems", International Journal of Control and Automation, vol. 6, (2013), pp. 61.

\section{Authors}

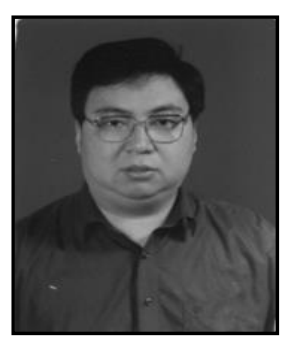

\section{Yin Daiyin}

He received his $\mathrm{PhD}$ in Oil and Gas Field Development Engineer from Daqing Petroleum Institute, China in 2001. He received his bachelor degree in Reservoir Engineering and master degree in Oil and Gas Field Development Engineer from Daqing Petroleum Institute, China in 1988 and 1993 respectively. And he was a Post-Doc of Institute of Mechanics, Chinese Academy of Sciences. Currently, he is a professor in Department of Oil and Gas Field Development Engineer in Northeast Petroleum University, China. His research interests include reservoir geological modeling, numerical simulation and dynamic analysis on the development of oilfield.

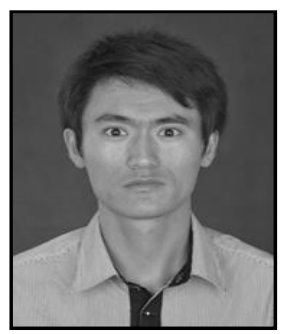

\section{Zhou Yazhou}

He received the master's degree in Oil and Gas Field Development from Northeast Petroleum University, China in 2009, and received the bachelor's degree in Petroleum Engineering from Daqing Petroleum Institute, China in 2005. Currently, he is a PhD Candidate in Oil and Gas Engineering at Northeast Petroleum University. His research interests include reservoir numerical simulation, theory and technology of oil and gas field development.

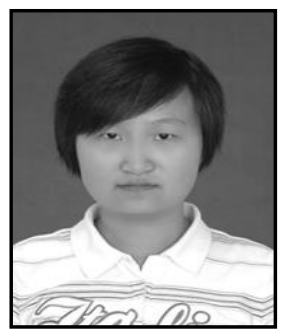

\section{Yuan He}

She received her bachelor degree in Petroleum Engineering from Northeast Petroleum University, China in 2011. Now she is a student of Oil and Gas Field Development Engineer in Northeast Petroleum University. Currently she is pursuing master degree.

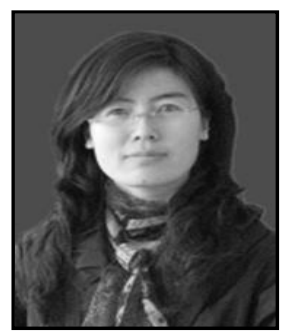

\section{Zhang Chengli}

She received her master degree in Oil and Gas Field Development Engineer from Daqing Petroleum Institute, China in 2006. She received her bachelor degree in Petroleum Engineering from Daqing Petroleum Institute in 2011. From 2010, she has been studying for a doctor degree in Oil and Gas Engineering in Northeast Petroleum University. Currently, She is a lecturer in the Department of Oil and Gas Field Development Engineer in Northeast Petroleum University. Her research interests include dynamic analysis on the development of oilfield, reservoir numerical simulation. 